\title{
Cultural Responsibility of Subjects in Moral Education in Colleges and Universities
}

\author{
Chunyan Chen \\ School of Marxism, Changchun University of Science and Technology \\ Changchun 130022, China \\ E-mail: gaogeyongjin@sina.com \\ Yinglin Li \\ College of Humanities, Jilin Agricultural University \\ Changchun 130118, China
}

Received: March 8, $2011 \quad$ Accepted: March 23, $2011 \quad$ doi:10.5539/ass.v7n7p159

\begin{abstract}
In a new era, to come to full understanding of the cultural responsibility of subjects in moral education in colleges and universities is an internal demand of modern educational theory for overall development of both teachers and students, and is the premise to play the leading role of teachers and mobilize the subjectivity of university students. At the same time, this also guides the direction for teachers and students to carry out moral education activities in colleges and universities. This article explains the responsibility of subjects in moral education in colleges and universities from the perspective of culture.
\end{abstract}

Keywords: Subject in moral education in colleges and universities, Culture, Responsibility

Teachers and universities are both subjects and objects of moral education in colleges and universities. In the process of moral education in colleges and universities, educators are subjects with respect to their own moral education activities, and university students and formation of their virtue as well as the moral issue are the objects of the moral education activities. In the meanwhile, the subjective status of university students in a specific moral education process can also not be denied. With respect to the moral education activities of teachers, students are the objects, whereas they are the subjects with respect to the moral education activities with the target of an ideal self. As the subjects of moral education with mutual connection and interaction, teachers and students bear the cultural responsibility that matches with their own role in a new era. Responsibility refers to the reasonable distribution of burden and role obligation of human as a society based on certain social division of labor, which is inescapable and can not be given up. As a matter of fact, as human body, their responsibility has already been endowed by the society. Marx and Engels ever said, "As a determinate and realistic man, you have rules, missions and tasks. Whether you have been aware of this does not matter at all". The reason why we emphasize responsibility of moral education subjects in colleges and universities is to enable contemporary teachers and university students to be more clearly aware of the historical mission they burden and then perform more consciously the obligations they are supposed to assume and become a really responsible one.

\section{Cultural responsibility of teachers}

Teachers are educators who impose influences upon students with a purpose and they take up a leading position in the process of moral education in colleges and universities. Teachers are organizers, executors and regulators of the process of moral education in colleges and universities, agents of certain social moral requirement and ideological morality, designers and leaders of moral education activities and implementators and moderators of influences of moral education and play a guiding role in the process of moral education activities in colleges and universities. The major task of teachers is to organize and control the process of moral education activities in colleges and universities, motivate and encourage formation of students' ideological morality and direct and regulate them to develop towards the direction of the target of moral education in colleges and universities. The occupation of moral education teachers in colleges and universities is a particular one that cultivates and moulds 
human and is a lofty occupation that is related with the future of the country and the nation. The key to development of China is education, the key to education is talent and the key to cultivation of talent is teacher. Teachers have to assume their own historical mission and perform the cultural responsibility that they should assume. From theoretical study on the role of teachers and their teaching duty at present, it can be found that teachers assume duties in several aspects in teaching.

The responsibility of teaching based on the law. The legal responsibility of teachers are mainly the cultural responsibilities formed by the six obligations stipulated in "Teachers Law of the Peoples Republic of China", namely, to observe disciplines and laws and to be a model of virtue for others; to carry out the educational policy of the nation, abide by rules and regulations, implement the teaching plan of the school, perform the teachers' contract and to complete the educational and teaching task; to conduct education of basic principles on students that is confirmed by the constitution, education of patriotism and national unity, education of legal system and education of ideological and morality, culture and scientific technology, and to organized and direct students to perform beneficial social activities' to care about and show concern for all students, to respect students' personality and to promote students' overall development in morality, intelligence and physical quality, etc.; to restrain behaviors that are harmful to students or other behaviors that violate students' legal interests and to criticize and stop phenomena that are helpful for healthy growth of students' to continue to improve students' ideological and political consciousness and their educational and teaching level. The above six obligations are the responsibilities endowed to the teachers by the law and are guaranteed to be carried out by the national compelling force. Moral education teachers in colleges and universities have to perform teaching pursuant to the law according to the above six responsibilities. Otherwise, any legal responsibility caused by fault of teachers has to be investigated pursuant to the law.

The responsibility of teachers to impart moral education knowledge. Teachers are required to impart social or class moral principles or standards and to teach university students to behave as a person who complies with certain social or class moral requirement. Thus, to explain teaching materials, to answer questions and to impart moral education knowledge is the most primary role of moral education teachers in the process of teaching. Of course, at the time when teachers impart knowledge, the key is to enable university students to learn how to learn in the process of receiving knowledge. Therefore, teachers should not only grasp relevant knowledge, but also have to grasp skills and technique to impart the knowledge, to arouse attention of university students and to cultivate their thinking mode.

The responsibility of teachers to impart knowledge and educate students. K. Jaspers said, education was communication of flesh between the subjects of human being, which included impartation of knowledge, comprehension of life connotation and standardization of will behavior, which passed cultural heritage down to a younger generation through the function of cultural transmission to let the younger generation to form freely and to start their liberal natural instincts. Then, as the subject of implementing moral education in universities, teachers not only should have the responsibility of imparting moral education knowledge, but also should have the responsibility to encourage formation of students' moral personality, enlightenment of their soul, improvement of their personality and enrichment of their life, and should motive the internal moral emotion and capacity of practical morality of university students to become one with liberal and comprehensive development. The task of moral education teachers in universities is to spread the Marxism-Leninism, Mao Zedong Thought, Deng Xiaoping Theory, the important thoughts of "Three Represents Theory" and Scientific Outlook on Development in the process of moral education in universities, to impart the central values of socialist, to improve university students' ability to analyze problems and resolve problems in the actual moral life, to cultivate university students' ideological and political consciousness, to consolidate the accurate ideological and political direction of university students, to foster the constructors and successors of socialist career and to mould the spiritual world of university students.

The responsibility of teachers in occupational morality. The occupational morality responsibility of teachers is one that is generated based on the obligation of occupational morality, which refers to the responsibility that teachers perform out of consciousness with due cognition in morality of responsibilities in the future based on knowledge in essence and developmental trend of moral education in colleges and universities. Thus, contemporary university moral education teachers have to set up the educational idea of facing up with the future and building the future, jump of the fence of exam-oriented education, pay attention to quality-oriented education and innovation education and attempt to cultivate innovative talents and qualified citizens with comprehensive development who correspond to demand of the society in the future. The occupational moral responsibility of teachers has the characteristics of accurate and rational educational ideas that correspond with demand of the times and is improvement and surpassing of teachers on other responsibilities. The occupational 
moral responsibility of moral education teachers in universities refers to conscious undertaking of moral obligation of university students and the society in the future, which is mainly manifested as self-discipline of inside belief of teachers. In one word, the responsibility of moral education teachers in universities is unification of legal obligation, occupational responsibility and moral obligation that should be burdened based on roles of teachers. External legal requirement and occupational standards of the society and inside belief of the subjects of moral education teachers in universities achieve unification of heteronomy and self-discipline of responsibility of moral education teachers in universities, and then realize sublimation of responsibility of moral education teachers in universities, and finally decide the value target of teachers' responsibility that complies with the teachers' rule and social developmental demand.

\section{Cultural responsibility of university students}

University students are educatees of the process of moral education. In the process of moral education, they do not merely negatively receive influences of educators, but take part in the process of education as the role of the subject of receiving, and play their positive initiative role in the process. In the process of interaction with education influences of educators, educatees conduct self education under direction of teachers, receive education influences and develop their own morality. At present, the responsibility of students is to love the responsibility of life, the responsibility of behavior and the responsibility of pursuing study and becoming useful persons.

The responsibility of university students to love life. The responsibility of university students to love life means a lot to university students. To love life is the process of exploring the value of life. The responsibility to love life is to love and to be loved to a certain extent. First of all, the responsibility is to love oneself, which is the premise and basis for all other responsibilities. Only when university students love their own and let themselves possess healthy body and mind, can they assume other responsibilities in their life. Then, it is the responsibility to love others. To love life of others and oneself is the foundation to be a human kind and is also the loftiest rule in the nature. To love his family, his friends and all those he acquaints with can further enhance the life responsibility of university students. Thirdly is the responsibility to love the nature. It is regression of human nature to love the nature. University students are required to have the responsibility to love the nature in order to set up and carry out the scientific outlook on development and speed up establishment of resource conserving and environment friendly harmonious society.

The responsibility of university students in their behavior. The behavior responsibility of university students is one which makes them conduct themselves and is one that should be possessed in order to learn to conduct oneself, to succeed at each stage of the life and to try to realize the life value to the best of one's ability. The behavior responsibility of university students includes survey and instructions on their behaviors prior to the behaviors, adjustment and supervision on their behaviors in the process and evaluation and introspection on the behaviors when the behaviors are over, so as to enable themselves to change and correct negative consciousness and behaviors, realize self-renewal of morality and perfection of personality, restrain the behavioral direction out of consciousness with correct social value standard and value measurement and to keep their behaviors in compliance with the social value and target. The behavior responsibility of university students is as small as daily behaviors, such as, industrious labor, unity and mutual aid, honest and trustworthy, observing disciplines and obeying laws, and hard work and plain living, etc, and is as large as the responsibility of serving the country worthily. Especially, the responsibility of serving the country worthily is extremely significant, since the destiny of the country is related with life development of each person and university students are grown up under cultivation of the country and, thus, the prosperity of the country and revitalization of nation is the obligatory responsibility of university students. Establishment of socialism with Chinese characteristics and the great rejuvenation of the Chinese nation requires university students today to establish their internal lofty belief with great enthusiasm, set up strong responsibility to render service to the country, maintain stability, unity and unification of the nation out of consciousness and grasp hard skills to render service to the country.

The responsibility of university students to pursue study and become useful persons. Currently, in the final analysis, the international competition is competition of talents. If a country and a nation intend to remain invincible in the international competition, a lot of talents are required. If an individual intends to gain victory in the life competition, he also has to become a useful person. As the future of the country and the hope of the people, university students should be determined to become useful persons, which is the obligatory responsibility of university students. University students have to grasp the opportunity to learn each day, work energetically to read, seek knowledge to go forward, enable themselves to become advanced special talents and assume the great mission endowed by the history. Therefore, the responsibility of university students to pursue study and become useful persons requires university students to be open-minded and to love the country, to be dedicated to the 
society, to be filled with self-confidence, to have self-esteem, to be honesty, to be independent in life, frugal and self-renewal, to be lenience, and cooperative, to be optimistic in choosing the employment, to be courageous and resolute and to be courageous to innovation, to learn to be active and to be arduous for exploration, to enable themselves to become creators of advanced productivity, constructors of advanced culture and maintainers of interests of the overwhelming majority of the people.

Confirmation of cultural responsibility of moral education teachers and students in universities is an important aspect for holding moral education activities in colleges and universities in the future. Only when they recognize clearly the cultural responsibility that exists at the same time among teachers and university students who interact with each other, can they not only take the initiative to play the leading role of teachers in the process of practicing moral education in universities, but can also mobilize positively the initiative of university students to better conduct moral education in universities and achieve the purpose of imparting knowledge and educating people. Only when they are clearly aware of the cultural responsibility of teachers and university students, can they carry out moral education in universities according to the definition of roles of their own and attain the purpose of practicing content of moral education out of consciousness.

\section{References}

(1965). Karl Marx and Frederick Engels, Vol. 3. Beijing: People’s Publishing House, p.329.

Gong, Haiquan. (2001). Moral Education in Universities in a New Century. Wuhan: Central China Normal University Press, 141. 